\title{
Torture and torture practices in Tanzania: Knowledge, attitudes and practices among medical professionals
}

\author{
Brenda Van Den Bergh, MSc, MPH*, Marie Brasholt, MD*, Praxeda James Swai, \\ MD, Mmed**, Primus Saidia, MD, Mmed, MSc**, Moses Kidew, CEO**, \\ Naomi Lipsius Hincheli, BSPH*, Maha Aon, MPH*, Jens Modvig, MD, PhD*
}

\section{Key points of interest}

- Many medical professionals in Tanzania report treating torture victims, but their general knowledge about torture is found to be low.

- Many medical professionals in Tanzania perceive that torture could be accepted under certain circumstances.

\footnotetext{
Abstract

Introduction: Medical professionals have a key role in addressing torture and need an awareness and knowledge of torture in relation to rehabilitation approaches, prevention and international standards. This study was undertaken with the aim of assessing the current knowledge, attitudes and practices of medical professionals in Tanzania, creating a baseline for possible future interventions. Methods: Both quantitative and qualitative data were collected. A cross-sectional survey was carried out using an interviewer-
}

*) DIGNITY - Danish Institute Against Torture

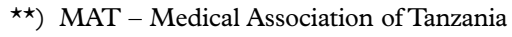

Correspondence to: rembrant_aarts@hotmail.com administrated structured questionnaire with 31 questions. Five focus group discussions were held. 386 medical professionals participated in the study representing primary, secondary and tertiary levels of health care in five regions of mainland Tanzania: Arusha, Dar es Salaam, Kigoma, Mara and Mbeya. Results: Around $95 \%$ of all professionals acknowledged the existence of torture in Tanzania, but only $7 \%$ could correctly identify six different acts as being actual acts of torture according to the definition of the UN Convention Against Torture and Other Cruel, Inhuman or Degrading Treatment or Punishment. Less than $15 \%$ were aware of relevant international standards like the Istanbul Protocol and the Mandela Rules. Up to $57 \%$ perceived that torture could be acceptable under certain circumstances. About $68 \%$ of all professionals reported to have encountered torture victims. The majority $(82.9 \%)$ saw themselves as competent in the management of torture victims, but only $22 \%$ had received training specifically focusing on torture and its consequences. Most were interested in learning more on the subject. Conclusion: While medical professionals may be aware of the 
existence of torture in the country and report encountering torture victims in their daily work, both the professionals' skills and attitudes with regards to torture require development to intensify the work against torture in Tanzania. Intervention strategies should target training in medical schools and in-service training for medical professionals at all levels within the health care system.

Keywords: Torture, Tanzania, KAP study, medical professionals

\section{Introduction}

The medical profession has a key role in addressing torture. This includes early identification, medical documentation of cases and rehabilitation of torture victims. Furthermore, the medical profession plays an important role in the prevention of torture, including by being part of independent monitoring mechanisms that visit places of detention. To prevent torture and to treat its victims, it is crucial that medical professionals have knowledge of torture and its consequences, and of key international standards such as the Istanbul Protocol (UN, 2004) and the World Medical Association's Tokyo Declaration (WMA, 1976).

Studies about medical professionals' and medical students' knowledge and attitudes with regards to torture have been carried out in the US, Mauritius, India, Israel and the US (Agnihotri et al., 2007; Bean et al., 2008; Benninga et al., 2017; Dubin et al., 2017; Sobti et al., 2000; Verma \& Biswas, 2005), but to our knowledge never in SubSaharan Africa.

Tanzania is a unitary presidential democratic republic and is classified by the World Bank as a low-income country, with a population of about 57 million (reference year 2017). ${ }^{1}$ The issue of human rights in Tanzania is complex. In July 2009, the UN Human Rights Committee issued its concluding observations after considering Tanzania's fourth periodic report submitted under article 40 of the International Covenant on Civil and Political Rights, expressing concerns about several human rights issues including gender-based violence, ill-treatment of detainees by law enforcement officials and failure to recognize and protect minorities and indigenous people (UN, 2009).

Tanzania has not ratified the UN Convention against Torture and other Cruel, Inhuman or Degrading Treatment or Punishment (UNCAT), but torture is prohibited in its Constitution (article 13(6) (e)) (United Republic of Tanzania, 1977). The exact prevalence and nature of torture and the number of torture victims in Tanzania are unknown. Individual cases of torture have, however, been documented by several human rights organizations (HRW, 2013; LHRC \& ZLSC, 2017) and a recent qualitative study by some of the authors of this article found that informants had been exposed to deliberate torture including advanced torture methods so far not reported (Aon et al., 2018).

The health system in Tanzania is decentralized and framed most explicitly by its National Health Policy. ${ }^{2}$ The role of the medical profession in combatting torture in Tanzania seems fairly limited to date. The authors have been unable to locate organizations providing specialized

\footnotetext{
https://data.worldbank.org/country/tanzania Accessible at: http://www.tzdpg.or.tz/fileadmin/ documents/dpg_internal/dpg_working_groups_ clusters/cluster_2/health/JAHSR_2017/8. The_Nat_Health_Policy_2017_6th_24_ October_2017.pdf
} 
rehabilitation for torture victims, even though a few institutions have handled trauma cases. Medical documentation of torture rarely takes place, and health professionals are not systematically involved in monitoring places of detention.

The immediate aim of this study was to assess the current knowledge, attitudes and practices of medical professionals in Tanzania regarding torture, as well as to assess the role that medical professionals see for themselves in relation to prevention of torture and treatment of torture victims. The study was undertaken in collaboration between the Medical Association of Tanzania (MAT) and DIGNITY-Danish Institute Against Torture, with a long-term view of involving the medical profession in Tanzania in anti-torture work.

\section{Methods}

The study used a sequential mixed-methods study design. Results included both quantitative and qualitative data, where quantitative data was collected first. A cross-sectional survey was carried out using an interviewer-administered, structured questionnaire consisting of 31 questions. In addition, five qualitative focus group discussions (FGDs) were conducted (one in each region included in the study). Both in the interviews and in the FGDs, participants were asked questions relating to their knowledge, and regarding torture and their awareness of international standards and protocols. The data collection took place in March 2016.

\section{Questionnaire and Focus Group Discussions} The questionnaire $\left(\operatorname{annex} 1^{3}\right.$ ) was developed

3 Please see the Torture Journal website (https:// tidsskrift.dk/torture-journal/issue/view/8380). in English and translated into Swahili. No part of the questionnaire contained items that captured the identity of the medical professionals beyond age, cadre, gender, and region/district in which they work. The questionnaires were administered by research assistants who all were medical doctors and Tanzanian nationals. All had received a one-day training on the study objectives, methodology and study tools prior to their field work. During the training, each question in the questionnaire was asked so that the interviewers could interpret its purpose. The various answers given during these pilot interviews enabled the facilitator to gauge what each question would mean to the interviewees. Each question was restructured so its correct interpretation could be presented to the medical professionals. Similarly, the Swahili translations were also presented to the interviewers so that they could see if the response would accord with the English meaning of the original question. Each interview lasted between 20 and 30 minutes.

A semi-structured interview guide was used to conduct the FGDs (annex $2^{4}$ ). The guide was translated from English into Swahili to ensure a smooth discussion. Probing was done following responses to the questions whenever necessary. The primary purpose of the FGDs was to gain a deeper understanding of the responses from the quantitative questionnaires. Each FGD was facilitated by two research assistants. One of the research assistants was the moderator of the discussion and the other one operated the recorder and took notes. All FGDs were audio recorded. The FGDs were conducted at the regional hospitals, referral hospitals

$4 \quad$ Please see the Torture Journal website (https:// tidsskrift.dk/torture-journal/issue/view/8380) 
and the national hospital, as these facilities included a good composition of participants from various fields of work. The FGDs lasted between 45 minutes and one hour and took place in the board rooms of the health facilities, out of hearing and sight of others to ensure the safety and privacy of the participants. All members were coded by numbers and the use of names was avoided throughout the discussions. The number of participants in the FGDs ranged from a minimum of seven participants in Arusha to twelve in Dar es Salaam.

\section{Sampling Procedures}

A multi-stage sampling approach was adopted. At the first stage, five zones of Tanzania were selected purposefully based on anecdotal information on the existence of various forms of torture. The selected zones were: North, East, West, Lake and Southern Highlands. At the second stage, from each zone one region was purposefully selected based on anecdotal information on the degree of torture within the regions in that zone. The regions chosen were Arusha (in the northern zone), Dar es Salaam (in the eastern zone), Kigoma (in the western zone), Mara (in the lake zone) and Mbeya (in the southern highlands zone). At the third stage, from the selected regions three districts were selected purposely based on the existence of public health facilities and the number of medical professionals available in those districts as obtained from the regional records.

\section{Study Participants}

The study involved medical professionals from all three levels of health care in Tanzania, i.e., the primary level (district hospitals and all facilities below), the secondary level (regional hospitals) and the tertiary level (zonal referral consultant hospitals and the national hospital). A medical professional was defined as any person practicing clinical medicine with a medical qualification, from a certificate (minimum two years training) up to $\mathrm{PhD}$ level. Although attempts were also made to include medical professionals working within prison settings in the study, these attempts were unfortunately unsuccessful. Permission from responsible authorities was not obtained, allegedly related to the nature of the study.

Convenient sampling was used to recruit the study participants at the health facilities involved. Medical professionals who were available during the days of data collection, and who consented to participate in the study, were included. Participants for the FGDs were purposefully selected to ensure representation of cadres and fields of work. No compensation or reward for participating in the study was provided.

A total of 92 medical professionals, the majority from Dar es Salaam, refused to participate in the study, or offered to fill in the questionnaire but did not return it (rejection rate $19,2 \%$ ). Of the 92 , half stated constraint of time due to busy work schedules as the reason for nonparticipation. However, a significant number (16 persons) requested to be excused due to security concerns. Another seven persons offered to complete the questionnaire but did not sign the consent form and were consequently excluded from the study.

\section{Data Analysis}

All quantitative data collected by means of the questionnaire was coded, cleaned and checked for inconsistencies. All questionnaires were included in the analysis. The data was entered into Statistical Package Software for Social sciences (SPSS) version 21 for analysis. Descriptive analysis was done, where results were summarized 
in tables and figures to reflect the study objectives and responses of the participants.

The audio-recorded FGDs were first transcribed word for word/ad verbatim and translated from Swahili into English. The files were analyzed using qualitative content analysis and NVivo software was used for the analysis. The transcripts were first analyzed by reading and re-reading to become familiarized with the data. Transcripts of whole FGDs were analyzed as a meaningful unit to ensure analysis of the context as well. Condensed meaningful units were formed through data reduction and read and re-read to extract codes. Similar codes were grouped together and through constant comparison these were abstracted into sub-categories, which were sorted to form categories to reflect the manifest content of the text.

The FGDs focused on the same topics as the questionnaire and aimed to gain a deeper understanding of the issues. In the analysis of the results, equal weight was given to both types of data and no data was left out of the analysis because of contradictions among responses.

\section{Ethical considerations}

This research obtained ethical approval from the National Institute for Medical Research (NIMR) in Tanzania. Permission to carry out the study was also obtained from the Regional Administrative Secretaries and District Executive Directors from the involved regions and districts. Besides ethical approval in Tanzania, the research obtained internal ethical approval within DIGNITY through the organization's ethical committee. Due to the nature of the study, the sensitivity of the topic and the imaginable defaming of the medical profession by possible immoral or disadvantageous results, specific attention was given to ensuring the safety of the participants. All participants were informed about the study objectives, how confidentiality would be ensured and how results would be disseminated, and they were asked for written informed consent at the beginning of the interviews and FGDs. Data was subsequently collected in a non-attributable and anonymous way, FGDs took place out of hearing and sight of others not participating in the study, and during the FGDs no names were used to guarantee as much as possible the participants' privacy and safety.

\section{Results}

A total of 386 medical professionals were interviewed according to the structured questionnaire and 5 FGDs were conducted with the number of participants ranging from 7 in Arusha to 12 in Dar es Salaam and a total of 49 participants altogether.

The mean age of the participants was 34 years (range 20-68 years) and $68.1 \%$ were male. Although the study was carried out in five specific regions, ten of the study participants were from other regions as they happened to be on the study sites during data collection and volunteered to participate. The regions they represented were Shinyanga (2), Singida (1), Manyara (1), Iringa (1), Kilimanjaro (1), Dodoma (1), Tanga (1), Coastal (1) and unknown region (1)..$^{5}$ Table 1 (see appendix ${ }^{6}$ ) also shows the socio-demographic characteristics of the study participants.

When medical professionals were asked whether they think torture takes place in their country, 95.6\% answered "yes". Participants in the FGDs commented that the prevalence

5 The region was unable to be identified during the analysis due to an omission in data collection on this question.

6 Please see the Torture Journal website (https:// tidsskrift.dk/torture-journal/issue/view/8380) 
of torture might be higher compared to the general perception because torture happens in secret: “...(the) magnitude of torture may be very high as in many cases our criminal justice system is involved in torturing people...police sometimes torture suspects under arrest...prisoners are tortured by prison officers... all these have nowhere to complain..." (FGD Member no. 4 - Region C).

However, the majority of the participants could not correctly identify acts of torture. When provided with a list of six acts of torture in the questionnaire (public officials giving electric shocks to a prisoner, blindfolding a prisoner for many hours, suspending the arms of a convict, beating and kicking a convict, isolating a prisoner from all other prisoners, and depriving a prisoner from food), only $7 \%$ of the medical professionals indicated all six answers as acts of torture. Moreover, a total of $13.7 \%$ indicated two or less, which reflects a relatively low level of knowledge.

The FGDs elicited further insights, where some participants confused torture with gender-based violence, and some defined torture as the deprivation of any human right: "...for me torture is any action done to someone to deprive him/her rights which s/he was supposed to get ... even not given certain service to a person is torture ... any act which is against human rights is torture." (FGD member no. 9 - Region C).

Respondents' knowledge on international standards and protocols was also found to be low. The UNCAT was shown to be best recognized ( $52 \%$ of the respondents). However, when asked whether the UNCAT focuses solely on people in places of detention, $18.3 \%$ wrongly answered "yes". Knowledge of the existence of the Istanbul Protocol and the Mandela Rules was shown to be very low (13.6\% and $17.3 \%$ respectively).
When asked about their attitudes towards the use of torture, $46.9 \%$ of all participants felt that torture was acceptable under certain circumstances or with certain persons, whereas $47.8 \%$ of the respondents perceived that torture should not be allowed under any circumstances, and $5.3 \%$ did not know. When asked whether torture should be allowed for acquiring 'life-saving information' from someone, an even higher number, $57 \%$, felt that torture should be allowed. The different points of view were reflected in the FGDs.

Some respondents viewed that, in light of modern science and technology, suspects can be interrogated without necessarily being tortured, and one of them stated, "... imagine someone has been tortured to confession of the crime s/he committed, if it was theft of property, justice will prevail to the owner of that property but how about the torture effects to this person? ... It is not justice to torture the suspect." (FGD member no. 4 - Region D).

Others felt that torture could be justified in certain instances: “...in my opinion, torture should be allowed in some issues of national interest, if one person endangers life of other people, for instance a terrorist, there should be a room for torture to that person...important is to ensure a controlled degree of torture..." (FGD member no. 8 - Region B). However, the majority of the respondents $(67.4 \%)$ were of the opinion that perpetrators should be punished in all cases.

When asked about their actual experience with victims of torture, the majority of the medical professionals stated that they had encountered both self-declared cases $(66.8 \%)$ and suspected cases (67.6\%). It should be noted that $57.3 \%$ had treated patients who were detainees at the time. These encounters gave rise to challenges, e.g., breach of medical confidentiality, which were not normally seen 
in their daily practices:

"...sometimes the police officer is with the client even at the consultation room...the victim will not tell the real story... you have to request the police to stay by the door side so at least he can speak, but still there is a lot of fear..." (FGD member no. 6 - Region D). The majority $(82.9 \%)$ reported that they felt competent at treating victims of torture. However, only $22 \%$ had covered torture issues and how to treat and document cases of torture as part of their medical education. When asked if they were interested to learn more about the physical and psychological effects of torture and about torture as a human rights issue, $98.4 \%$ answered "yes", and $96.6 \%$ were interested in taking up training to become a counsellor for victims of torture to be able to provide treatment, counselling and rehabilitation. A total of $94.8 \%$ of the medical professionals recommended that the subject of medical treatment and documentation of cases of torture should be included as a special module in the curriculum of the medical education.

Most participants indicated that they would report a torture case to at least one institution (e.g., legal authorities, Commission for Human Rights and Good Governance (the national human rights institute), Legal and Human Rights Center (a Tanzanian NGO dealing with human rights violations), Medical Association of Tanzania), but $8 \%$ did not know what they would do if they encountered a victim of torture or specifically said that they would not report it to anyone nor take any action. Some participants admitted that most of the time they focused on physical treatment alone, as they were not aware of what should be done next: "... the challenge we have, me specifically, I do not know about others... When we encounter a torture victim, we know that our role is medical care, treat the physical wounds resulted from that torture... I cannot go further..." (FGD member no. 4 - Region A).

When asked if they saw a need in Tanzania for the establishment of rehabilitation centers for torture victims, 96.6\% answered "yes" and 2.3\% "no", while $1.1 \%$ did not know. Most of the FGD participants stated that a rehabilitation center is important and needed in the country: “...to my side, rehabilitation of a tortured victim is very important for several reasons... Victim may have been affected physically... psychologically and mentally..." (FGD member no. 7 - Region A).

When data were analyzed further, no statistically significant gender differences were found except for significantly more men than women being of the opinion that perpetrators of torture should be punished in all cases $\left(x^{2} p\right.$ value $\left.=0.032\right)$.

\section{Discussion}

A considerable number of medical professionals in this study perceived that torture takes place in Tanzania, and at least two-thirds had come across victims of torture or suspected victims of torture in their daily practice. To our knowledge, no systematic studies have been done on the prevalence of torture in the country. However, the findings are consistent with the experience of human rights organizations and with the general impression of the authors that torture may be the rule rather than the exception in the investigation of criminal cases in the country and is also linked with the security forces. ${ }^{7}$

Some medical professionals were not

7 This impression is based on the extensive experience of the authors with working on human rights issues in Tanzania. 
willing to participate in the study, citing concerns about their own security. Some explicitly cited the case of Dr. Steven Ulimboka, who was severely tortured in 2012 during a doctor's strike. The perpetrators were never identified. Thus, torture is deemed to be a very real risk if the medical professionals are too outspoken. This gives an indication of how the presence of torture in Tanzanian society may lead to fear and self-censorship.

Often medical professionals are a first point of contact for torture victims (Eisenman \& Kim, 2000), and awareness and accurate identification is necessary for an informed history taking and physical examination of the patients and the subsequent planning of treatment and rehabilitation. However, only few medical professionals in this study could correctly identify acts of torture and many confused the meaning of torture with that of gender-based violence or human rights violations in general. The results might be influenced partly by the fact that medical professionals, as defined in this study, included professionals from all professional levels in the country including the so-called 'specific cadres', i.e., professionals trained at certificate level with only two years of training. However, all medical professionals interviewed attend to patients, and they may come in contact with victims of torture. It is therefore a necessity that knowledge of torture is ensured amongst all professionals.

In the study, $12 \%$ reported that they did not feel competent to treat torture victims. This is a very small figure considering that the majority of the medical professionals did not receive any training on torture during their medical education. This proportion involved professionals ranging from specialists by training to those in the least trained cadres. Lack of training on torture among medical professionals is not unique to Tanzania. In a clinical review on the role of doctors in investigation, prevention and treatment of torture in the United Kingdom, McColl, Bhui and Jones documented that there is lack of education on torture and related ethical and legal issues at undergraduate and postgraduate level and that many doctors are not aware of opportunities to work with organizations for the prevention of torture in the UK (McColl et al., 2012). To be able to attend to torture victims, one needs to be knowledgeable on torture issues. Lack of training on torture issues among medical professionals, in a country where torture acts exist, poses a question on the quality of care that torture victims receive.

Tanzania is among the countries that lack rehabilitation centers for torture victims. Not only is training on torturerelated issues lacking, also is the national health policy silent on torture issues. The findings indicate that a high proportion of the medical professionals lack knowledge on torture issues, and due to a general lack of well-trained staff-especially mental health staff - in the Tanzanian health care system, an integrated treatment approach is often likely to be lacking.

Our findings show that medical professionals in Tanzania have limited capacity to refer torture victims given the low proportion (30\% in some cadres) that is aware of the different organizations dealing with torture. Advocacy and training are needed to raise awareness of the existence of the (so far few) bodies in Tanzania that can provide help to victims of torture, and of the need for more organizations to offer those services.

The fact that a large proportion (up to $57 \%$ ) of the medical professionals deemed torture to be acceptable under certain 
circumstances is deeply concerning, but is similar to what has previously been seen among medical students in the US, Mauritius, and India (Bean et al., 2008; Dubin et al. 2017; Agnihotri et al, 2007; Verma \& Biswas, 2005), among physicians in India (Sobti et al., 2000), and among physicians and medical students in Israel (Benninga et al., 2017). Acceptance of torture is patently in complete opposition to the general medical ethical principle of 'do no harm'. It also raises questions on their deeper understanding of the consequences of torture. The physical and/or psychological consequences of torture may have a devastating and a lifetime effect and may influence not only the individual but also his or her family and society at large (Alayarian, 2009; Carinci et al., 2010). The finding points to the importance of including the topic in the curricula of medical professionals.

Some medical professionals would not report a case of torture to the relevant authorities. The reasons for this were not further investigated in the study, but one might speculate that it is due to the fear of becoming involved with police or security forces. This could contribute to long-term sequelae to victims of torture due to denial of some rights and compensation which they might have received following legal support. Health facilities are, in most cases, the first point of contact to help torture victims. A well-prepared health care system that will support the victims physically, socially and psychologically is very much needed (McColl et al., 2012; Mollica, 2011; Kanchan et al., 2007).

\section{Limitations}

One obvious limitation of this study is the fact that many respondents could not correctly identify torture. Responses should be viewed in that light. For example, the proportion that has actually treated torture victims may be lower than reported because they may have included victims of spousal violence. The same type of over-reporting may have influenced the high proportion of respondents believing that torture takes place in their country.

The data collection was made by doctors. Given the perceived hierarchy between professions, this may have limited some medical professionals from expressing their true attitudes and practices with regard to torture. Furthermore, some participants may have been reluctant to share their views given that the interviews and FGDs were administered by someone they did not know, took place at their workplace and-with the FGDs-in the presence of colleagues. The results may therefore be affected by information bias.

Because the data collection in this study adopted convenient sampling and not a random sampling strategy, we must conclude that the observed proportions of professionals' knowledge, attitudes and practices may not be nationally representative. For instance, election of zones with anecdotal information on the occurrence of torture may have caused on overestimation of the perceived occurrence of torture by medical professionals.

However, considering the design of this study, the careful selection of the regions with varying characteristics and the inclusion of medical professionals from all cadres, the study provides comprehensive baseline information on the prevailing situation regarding torture knowledge, attitudes and practices among medical professionals in Tanzania. The use of a mixed-methods approach and the consistency between quantitative and qualitative data make the study findings more reliable (Tashakkori \& Teddlie 1998). 


\section{Conclusion}

Torture is prohibited in Tanzanian law, but the country is still far from having implemented this prohibition and has not yet ratified the UNCAT. Medical professionals may play an important role in raising awareness of the extent to which torture happens in the country, and in treating those who suffer the immediate or chronic effects of torture. The results of this study, together with the reports from NGOs, form the baseline on which intervention strategies and further investigations may be developed. Such initiatives would aim at developing a comprehensive anti-torture strategy for the country considering the important role that medical professionals play in this endeavor. One obvious place to start is in medical schools and with postgraduate training for medical doctors and other health professionals.

\section{Acknowledgements}

The authors would like to express great thanks to the Hospital Directors, the District and Regional Medical Officers, the Heads of the facilities and all medical professionals who participated in the study. Moreover, the authors wish to thank the research assistants, the secretariat of the MAT and the National Institute for Medical Research in Tanzania for making this study possible.

\section{Funding}

The Danish Ministry of Foreign Affairs kindly helped to fund this study.

\section{References}

Agnihotri A. K., Purwar B., and Jeebun N. (2007). Awareness of issues related to torture among medical students in Mauritius. Indian fournal of Medical Ethics, 4(3). https://doi.org/10.20529/ IJME. 2007.053

Alayarian A. (2009). Children, torture and psychological consequences. Torture fournal, 19(2),145-56.
Aon M., Sungusia H., Brasholt M., Van Den Bergh B., Modvig J. (2018). Voices of torture survivors in Tanzania, a qualitative study. Torture fournal, 28(3), 92-103. https://doi.org/10.7146/torture. v28i3.111199

Bean J., Ng D., Demirtas H., and Guinan P. (2008). Medical students' attitudes toward torture. Torture fournal, 18(2): 99-103.

Benninga Z., Steiner-Birmanns B., Arbel R., Abu Akar F. and Aboo Di M. (2017). Recognition and treatment of law enforcement violence against detainees and prisoners: A Survey among Israeli physicians and medical students. Torture fournal, 27(1), 42-50. https://doi.org/10.7146/ torture.v27i1.26533

Carinci A. J., Mehta P., and Christo P. J. (2010). Chronic pain in torture victims. Current Pain and Headache Reports 14(2), 73-79. https://doi. org/10.1007/s11916-010-0101-2

Dubin K., Milewski A. R., Shin J. and Kalman T. P. (2017). Medical student attitudes towards torture, Revisited. Health and Human Rights 2017, Dec;19(2), 265-277.

Eisenman D. P., Keller A. S., and Kim G. (2000). Survivors of torture in a general medical setting. Western fournal of Medicine 172(5), 301-4. https:// doi.org/10.1136/ewjm.172.5.301

HRW (2013). Tanzania's Victims of Torture. Human Rights Watch. Think Africa Press, 26 fune 2013.

Kanchan T., Kumar T. S. M., Kumar G. P., and Yoganarasimha K. (2007). Torture and Role of Medical Practitioners. $\mathscr{F K}$ Science, $9(1)$.

LHRC \& ZLSC (2017). Tanzania Human Rights Report 2017. Legal and Human Rights Centre and Zanzibar Legal Services Centre, Tanzania, 2017.

McColl H., Bhui K., and Jones E. (2012). The role of doctors in investigation, prevention and treatment of torture. Fournal of the Royal Society of Medicine 105(11), 464-71. https://doi. org/10.1258/jrsm.2012.120100

Mollica R. F. (2011). Medical best practices for the treatment of torture survivors. Torture fournal, 21(1), 8-17.

Sobti J. C., Chapparawal B. C. and Holst E. (2000). Study of knowledge, attitude and practice concerning aspects of torture. $\mathcal{F}$ Indian Med Assoc,, 98(6), 334-5, 338-9

Tashakkori A. and Teddlie C. (1998). Applied social research methods series, Vol. 46. Mixed methodology: Combining qualitative and quantitative approaches. Thousand Oaks, CA, US: Sage Publications, Inc.

UN (2004). Istanbul Protocol: Manual on the Effective Investigation and Documentation of Torture and Other Cruel, Inhuman, or Degrading Treatment or Punishment. Rev. 1. Professional Training Series, 
no. 8/rev. 1. Office of the United Nations High

Commissioner for Human Rights, Geneva, 2004.

UN (2009). Consideration of reports submitted by states parties under article 40 of the covenant. Concluding observations of the Human Rights Committee. United Republic of Tanzania. UN Human Rights Committee, Ninety-sixth session Geneva, 13-31 July 2009.

United Republic of Tanzania (1977). The Constitution of the United Republic of Tanzania of 1977.

Verma S. K. and Biswas G. (2005). Knowledge and attitudes on torture by medical students in Delhi. Torture fournal, 15(1), 46-50.

WMA (1976). WMA Declaration of Tokyo - Guidelines for physicians concerning torture and other cruel, inhuman or degrading treatment or punishment in relation to detention and imprisonment. World Medical Association, 1979. 